Published in "Journal of Vertebrate Paleontology 34(6): 1317-1328, 2014"

which should be cited to refer to this work.

\title{
A REASSESSMENT OF THE LATE JURASSIC TURTLE EURYSTERNUM WAGLERI (EUCRYPTODIRA, EURYSTERNIDAE)
}

\author{
JÉRÉMY ANQUETIN*,1,† and WALTER G. JOYCE ${ }^{2}$ \\ ${ }^{1}$ UMR CNRS 7207 MNHN UPMC, Muséum National d'Histoire Naturelle, CP38, 8 rue Buffon, 75231 Paris cedex 05, France, \\ j.anquetin@gmail.com; \\ ${ }^{2}$ Department of Geosciences, University of Fribourg, Chemin du Musée 6, 1700 Fribourg, Switzerland, walter.joyce@unifr.ch
}

\begin{abstract}
Eurysternum wagleri is one of the first named, yet most poorly understood turtles from the Late Jurassic of Europe. Over the years, many specimens have been referred to and many species synonymized with E. wagleri, but little consensus is apparent, and the taxonomy is therefore highly confusing. Based on the rare, only known illustration of the lost holotype and on the reassessment of select individuals, the species E. wagleri is recharacterized herein. Eurysternum wagleri is diagnosed by a deep pygal notch, a carapace with a pentagonal outline, a contribution of vertebral 5 to the posterior carapace margin, three cervical scales, very wide vertebral scales with a well-developed radiating pattern, well-developed costoperipheral fontanelles in medium-sized individuals, a plastron connected to the carapace by ligaments, gracile, peg-like bony projections of the hyo- and hypoplastra, and large, oval-to-quadrangular lateral plastral fontanelles. A lectotype is designated for Acichelys redenbacheri, and this taxon is interpreted as the junior subjective synonym of Eurysternum wagleri. All other, previously proposed synonymies are rejected, because they lack characters that would allow diagnosing them as E. wagleri.
\end{abstract}

\section{INTRODUCTION}

The Late Jurassic of Europe is characterized by an endemic assemblage of littoral, eucryptodiran turtles, which are currently referred to the taxa Plesiochelyidae, Eurysternidae, and Thalassemydidae (Lapparent de Broin, 2001; Danilov, 2005). The Late Jurassic lithographic limestones of southern Germany have been particularly important for the understanding of this fauna, because they produced a great number of often well-preserved specimens that also served as the holotypes of numerous taxa (e.g., Meyer, 1839a, 1839b, 1860, 1864; Wagner, 1853; Zittel, 1877). Based on this profusion of material, various authors (e.g., Meyer, 1860; Maack, 1869; Zittel, 1877) throughout the 19th century recognized these fossil turtles as being different from modern faunas and placed them in their own taxonomic units (genera). However, little attention was accorded to these forms during the 20th century, and they are now in need of serious taxonomic revision.

One of the first named, yet most poorly understood taxa from the Late Jurassic of Europe is Eurysternum wagleri Meyer, 1839 b. This is due to a number of reasons (Joyce, 2003). First, $E$. wagleri is based on an incomplete specimen that only shows details of the pygal region in ventral view (Fig. 1). Second, Meyer (1839b) did not see the holotype when describing this taxon, but rather described it based on an illustration. Third, like so many others, the holotype of E. wagleri was destroyed in Munich during World War II (Wellnhofer, 1967), making it impossible to scrutinize the morphology described by Meyer (1839b). Fourth, comparison of the few surviving holotypes of other Late Jurassic turtles described during the 19th century with their type illustrations commonly reveals great

*Corresponding author. ${ }^{\dagger}$ Current address: Section d'archéologie et paléontologie, Office de la culture, République et Canton du Jura, Hôtel des Halles, 2900 Porrentruy, Switzerland. discrepancies between the two (Joyce, 2003). Type illustrations are therefore not a reliable source of genuine morphological information.

In parallel with naming a profusion of species throughout the 19th century, authors synonymized taxa using rationales that do not correspond to modern taxonomic practice. Given that $E$. wagleri is one of the first fossil turtles to be named, many Late Jurassic turtles from Germany and France were synonymized with it, including Aplax oberndorferi Meyer, 1843, Achelonia formosa Meyer, 1860, Acichelys redenbacheri Meyer, 1854, Euryaspis radians Wagner, 1861, Hydropelta meyeri (Thiollière, 1850), Palaeomedusa testa Meyer, 1860, Parachelys eichstaettensis Meyer, 1864, and Thalassemys marina Fraas, 1903 (e.g., Rütimeyer, 1873; Zittel, 1877; Fraas, 1903; Oertel, 1915; Bräm, 1965). A persistent idea is that Aplax oberndorferi represents an early ontogenetic form of E. wagleri, whereas Acichelys redenbacheri and, most notably, Palaeomedusa testa (both typified by bigger individuals) are adult forms of E. wagleri (e.g., Broin, 1994; Lapparent de Broin et al., 1996). However, given the fragmentary nature and loss of the holotype, most authors utilize the morphologies displayed by the alleged synonyms of E. wagleri when discussing the anatomy or relationships of this species. The resulting taxonomic situation is therefore extremely confusing.

Eurysternum wagleri was historically diagnosed by its characteristic deep pygal notch, but little attention was accorded to the details in this area. Joyce (2003) recently noted that a deep pygal notch is found in a number of turtles from the lithographic limestones of southern Germany, but that significant variation is apparent among these notched turtles. It was therefore unclear whether this feature was diagnostic for a single species or a more inclusive clade of deeply notched taxa. In particular, Joyce (2003) noted that the holotype of E. wagleri (or at least its illustration) appears to have had supernumerary bones (twelfth peripherals?) in the pygal area, whereas a specimen referred to this species by Zittel (1877) lacks these bones. A previously undescribed specimen housed in Munich (BSPG 1960 VIII 43) 


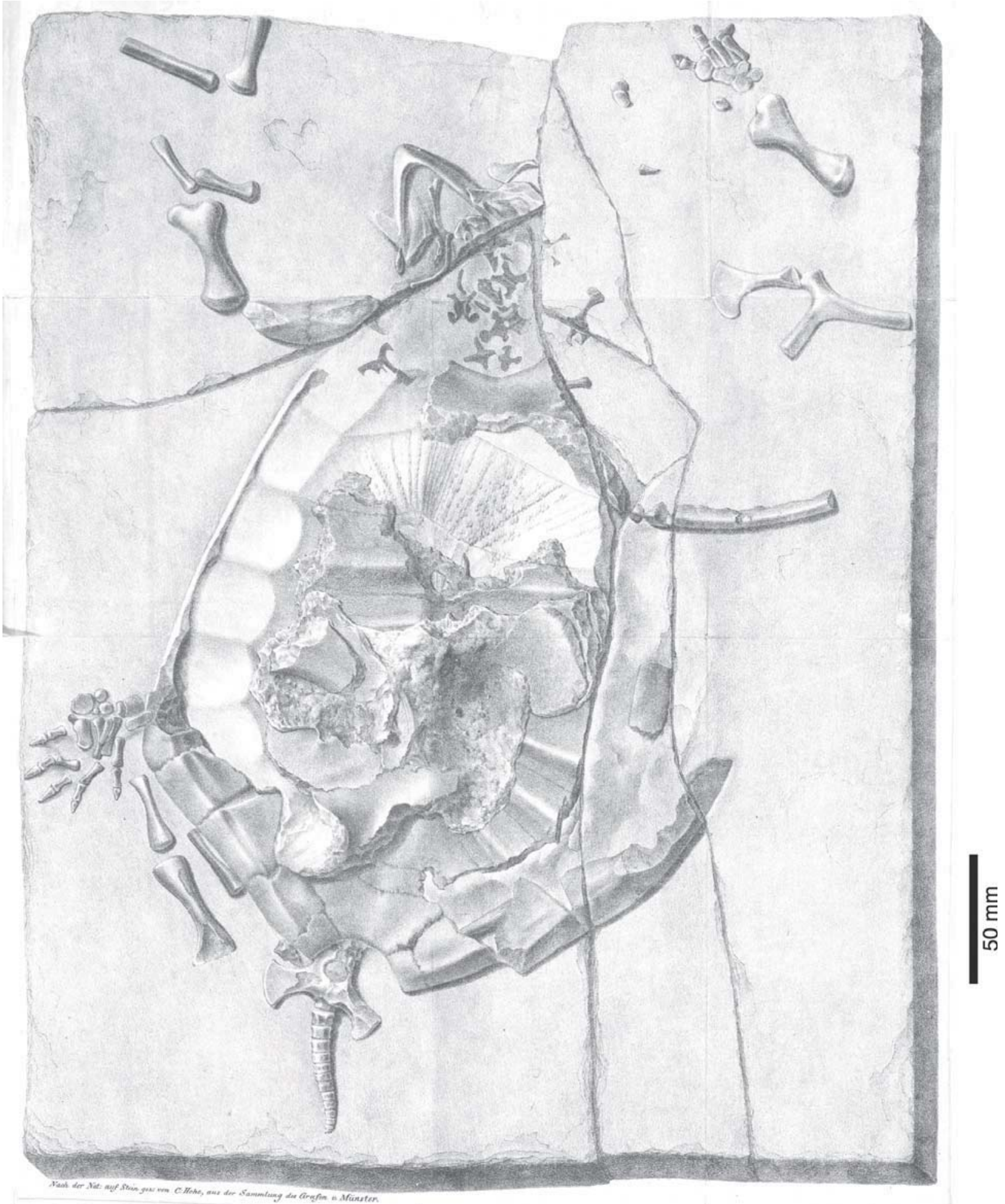

FIGURE 1. Photograph of the illustration of the lost holotype of Eurysternum wagleri, Late Jurassic of Solnhofen, Germany. This illustration was published as a separated annex to Meyer (1839a) and is missing from many libraries (see text). This is the copy bound with the volume housed in the library of the Natural History Museum, London.

presents a similar morphology to that seen in the holotype, thereby suggesting that the illustration of the type specimen is correct, at least regarding this particular point. However, a review of turtles from the Late Jurassic of southern Germany now leads us to the conclusion that all turtles with a deep pygal notch actually share a number of other characteristics that support their placement in the same species.

The purpose of the present study is to characterize the morphology of Eurysternum wagleri based on a small number of selected individuals, including the herein newly designated 
lectotype of Acichelys redenbacheri. Correctly or not, many undescribed specimens in museum collections have been assigned to E. wagleri. This work will hopefully be a reference for the correct identification of these specimens in the future and will serve as the basis for integrating this taxon into global phylogenetic analyses.

Institutional Abbreviations-BMM, Bürgermeister-MüllerMuseum, Solnhofen, Germany; BSPG, Bayerische Staatssammlung für Paläontologie und Geologie, Munich, Germany; CM, Carnegie Museum of Natural History, Pittsburgh, U.S.A.; MNB, Museum für Naturkunde, Berlin, Germany; MNHN, Muséum national d'Histoire naturelle, Paris, France; NMS, Naturmuseum Solothurn, Solothurn, Canton of Solothurn, Switzerland; SMF, Senckenberg Naturmuseum, Frankfurt-am-Main, Germany.

\section{SYSTEMATIC PALEONTOLOGY}

TESTUDINES Batsch, 1788

EUCRYPTODIRA Gaffney, 1975a

EURYSTERNIDAE Dollo, 1886

Remarks-Late Jurassic eucryptodires from Europe are usually referred to one of the three following families: Eurysternidae Dollo, 1886, Plesiochelyidae Baur, 1888, and Thalassemydidae Zittel, 1889. Usage of these names has been highly inconsistent throughout the 19th and 20th centuries, but all three names remain in regular usage (e.g., Bräm, 1965; Lapparent de Broin, 2001; Danilov, 2005). The presence of three cervical scales in Eurysternum wagleri (see below) and other accumulating evidence (unpublished data) suggest that these three families may actually form a monophyletic group, which collectively may be named Plesiochelyidae following the provisional definition proposed by Püntener et al. (2014). Until more evidence is found, however, we prefer to avoid creating more confusion and use Eurysternidae sensu Lapparent de Broin et al. (1996). As such, eurysternids are considered to include such taxa as Eurysternum wagleri, Solnhofia parsonsi Gaffney, 1975b, and Idiochelys fitzingeri Meyer, 1839a.

\section{EURYSTERNUM WAGLERI Meyer, 1839b (Figs. 1-6)}

\section{Eurysternum wagleri Meyer, 1839b:75 (original description).}

\section{Synonymy-Acichelys redenbacheri Meyer, 1854.}

Type Material-Eurysternum wagleri is based on a single specimen, which is the holotype by monotypy. The holotype was last housed in Munich, but is now considered lost (Wellnhofer, 1967). A poorly crafted cast exists in the collections of the Sedgwick Museum of Earth Sciences in Cambridge, U.K., but it reveals none of the details that are apparent from the type illustration (Joyce, 2003).

Illustration of Type-Meyer (1839c, no plate number; see remarks below); Figure 1.

Type Horizon and Locality-Late Jurassic (Tithonian), lithographic limestone quarries of Solnhofen, Germany.

Referred Specimens-BSPG AS I 921 (Zittel, 1877:pl. XXVII; Figs. 2-3) and BSPG 1960 VIII 43 (Fig. 4) from the quarries of Denkendorf/Zandt, Germany; MNB R 2440, lectotype of Acichelys redenbacheri (Figs. 5-6) from the quarries of Solnhofen, Germany (see Discussion).

Emended Diagnosis-Moderately sized turtle (carapace length up to $400 \mathrm{~mm}$ ); cranium about $20 \%$ of carapace length; carapace pentagonal in outline with greatest width at the level of peripherals 7-8; wide nuchal notch formed entirely by a broad, trapezoidal nuchal; carapace margin slightly concave between peripherals 8-11; deep pygal notch, possibly formed by the loss of the pygal bone; three cervical scales, of which the median one is very wide; vertebral scales very wide, covering more than half of the length of the costals; well-developed radiating pattern on vertebrals 2-4; fifth vertebral scale posteriorly contributing to carapace margin; plastron with a large, central fontanelle that is wider than long; quadrangular to oval lateral plastral fontanelles; ligamentous bridge; axillary process reaching to the level of peripheral 2; epiplastra and entoplastron very reduced or not ossified; absence of median suture between the hyoplastra, hypoplastra, and xiphiplastra; probable xiphiplastral fontanelle closed posteriorly by peg-like projections of xiphiplastra. Differing from Solnhofia parsonsi in cranium only $20 \%$ of carapace length; gracile peg-like plastron projections present in the bridge area; plastron less ossified. Differing from Idiochelys fitzingeri in complete series of neurals; presence of a central plastral fontanelle. Differing from Parachelys eichstaettensis in phalangeal formula (manus and pes) of 2-3-3-3-3. Differing from Palaeomedusa testa in significantly broader cervical region.

Remarks-It should be noted that the original illustration of the holotype specimen by C. Hohe was apparently added to the 1839 volume of Neues Jahrbuch für Mineralogie, Geognosie, Geologie und Petrefaktenkunde after its effective publication. We have been unable to find this illustration in several renowned libraries (e.g., Muséum national d'Histoire naturelle, Paris; Yale University; Harvard University; New York Public Library), save for the library of the Natural History Museum, London (NHMUK). A note on the illustration in the NHMUK volume states that they were not always bound together. This is confirmed by the absence of a plate number on the illustration and the fact that there is no reference to it in Meyer (1839c). This rare illustration of the holotype specimen is reproduced in Figure 1.

The single most diagnostic feature of Eurysternum wagleri is the formation of a deep pygal notch. The holotype was preserved on its back and the distribution of the scales therefore cannot be seen in the illustration. However, in all other turtles from the Late Jurassic of southern Germany that have a deep pygal notch, vertebral 5 contributes to the posterior carapacial margin (see descriptions below). We therefore diagnose this taxon primarily on the basis of these two traits.

\section{DESCRIPTION OF THE HOLOTYPE}

As discussed above, the situation is rather delicate when considering the holotype of Eurysternum wagleri because this specimen is now lost and because the only known illustration was never checked for accuracy by Meyer (1839b). The specimen, as depicted, consisted of a partial carapace in visceral view, but only the posterior part was satisfactorily preserved. Some remnants of the plastron might have been present in the central part of the fossil, but this remains conjectural. Anteriorly, the carapace was broken and revealed the imprint of a wide vertebral scale with a clear radiating pattern. Associated with the carapace were the disarticulated remains of the forelimbs, the cervical vertebrae, the lower jaw, and the right hind limb. In contrast, the pelvic girdle and the tail were preserved more or less in articulation. The pelvic girdle appears to have been positioned dorsal to the carapace, which is rather surprising. This was probably the result of postmortem dislocation. According to Meyer (1839c), the estimated length of the carapace was $250 \mathrm{~mm}$. This indicates that the original illustration was executed at natural size.

As far as it can be trusted, the original illustration (Fig. 1) exhibits a certain number of features that also occur in combination in several other Late Jurassic turtles from southern Germany. These features include a pentagonal shell outline with its greatest width at the seventh or eighth peripheral; presence of a nuchal notch; a wide, trapezoidal nuchal; very wide vertebral scales with a well-developed radiating pattern; posterolateral 

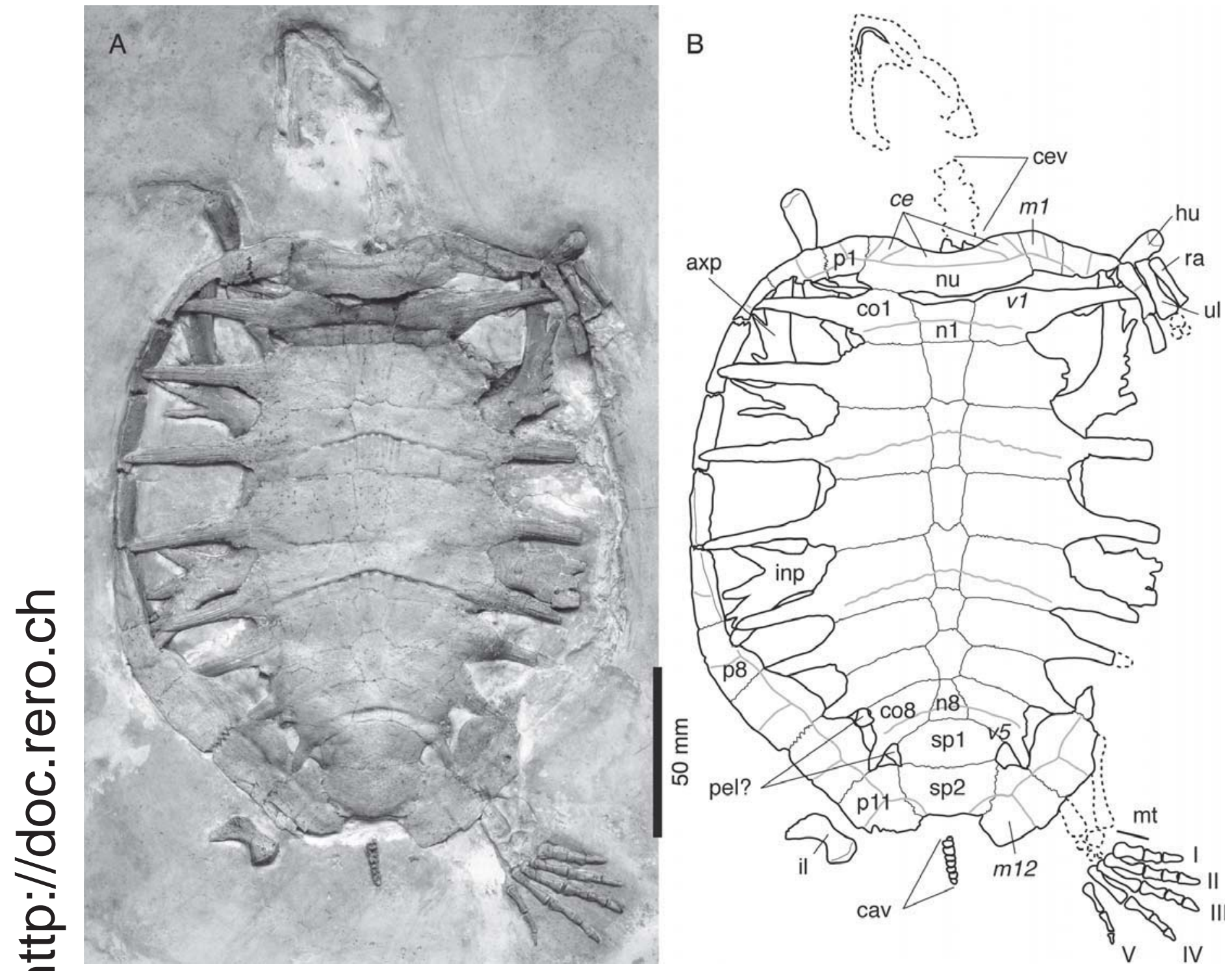

FIGURE 2. BSPG AS I 921, Eurysternum wagleri, Late Jurassic of Denkendorf/Zandt, Germany. A, photograph of specimen; B, interpretative line drawing. Abbreviations: I-V, digits I through V; axp, axillary process; cav, caudal vertebrae; ce, cervical scale; cev, cervical vertebrae; co, costal; hu, humerus; il, ilium; inp, inguinal process; m, marginal scale; mt, metatarsals; n, neural; nu, nuchal; p, peripheral; pel, pelvis; ra, radius; sp, suprapygal; ul, ulna; $\mathbf{v}$, vertebral scale.

border of the carapace from peripherals $8-11$ slightly concave; and, undoubtedly the most diagnostic feature of all, the presence of a deep pygal notch. This combination of characters is unique among all turtles familiar to us and therefore fully sufficient to diagnose the species E. wagleri.

Other characteristics of special interest are either difficult or impossible to observe in the type illustration. For example, the extent to which the costal bones are ossified is mostly ambiguous, although the apparent presence of a small fontanelle on the left side of the first suprapygal seems to indicate that the ossification of the costals was not complete in this specimen (to be compared with BSPG AS I 921). The number of cervical scales on the nuchal is also unclear.

As mentioned above, the illustration of the holotype indicates the presence of a pair of supernumerary bones (twelfth peripherals?) forming the sides of the pygal notch (Fig. 1). The presence of this pair of bones is now impossible to confirm. However, a specimen housed in Munich (BSPG 1960 VIII 43; see below) suggests that the illustration of the type specimen was probably correct regarding this particular point.

\section{DESCRIPTION OF BSPG AS I 921}

BSPG AS I 921 was originally described by Zittel (1877) and identified as a new specimen of Eurysternum wagleri. The specimen, which originates from Denkendorf/Zandt, Germany, consists of a relatively complete carapace, but only parts of the plastron are visible because the specimen is not prepared on both sides. Remains of the skull and the cervical series are also present, but too poorly preserved to provide significant insights. The appendicular skeleton is limited to the humeri, the right radius and ulna, and a partial right hind limb. Posteriorly, a series of eight caudal vertebrae and an ilium are also present (Fig. 2). The total carapace length between the nuchal and pygal notches is about $166 \mathrm{~mm}$. 


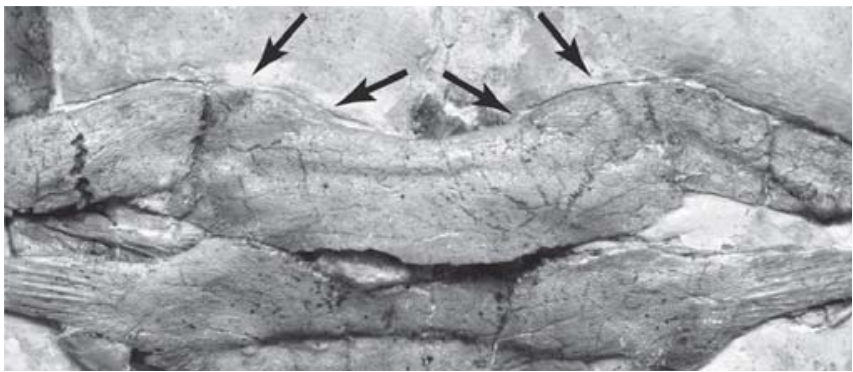

FIGURE 3. BSPG AS I 921, Eurysternum wagleri, Late Jurassic of Denkendorf/Zandt, Germany. Detailed photograph of the nuchal bone showing the lateral sulci of the three cervical scales (indicated by arrows).

The outline of the carapace greatly resembles that of the holotype of E. wagleri: a moderate, but wide nuchal notch, carapace pentagonal in outline with the greatest width at the level of the seventh and eighth peripherals, posterior margin (between peripherals 8 and 11) slightly concave, and deep pygal notch. The nuchal is trapezoidal and very wide. As already noted by Bräm (1965:166), there are three cervical scales in this specimen (see Discussion, below), of which the median one is significantly wider than the two lateral ones (Fig. 3). This configuration recalls the condition in the holotype and referred specimens of Palaeomedusa testa (e.g., Joyce, 2003), but the median cervical is significantly wider in E. wagleri. There are eight neurals: neurals 1 and 2 are trapezoidal and wider anteriorly, neurals 3-7 are hexagonal and elongated with the shortest sides anteriorly, and neural 8 is trapezoidal, very narrow anteriorly and wider posteriorly. There are two rather large and equidimensional suprapygals (see Discussion for considerations on the homology of the elements in the pygal region). The second suprapygal forms the median part of the deep pygal notch. There are eight costals, most of which are only ossified for about half of their length. As a result, the carapace retains well-developed lateral fontanelles. The distal ends of the posterior costals only insert rather superficially into the peripherals, a condition reminiscent of that seen in Asian sinemydids, such as
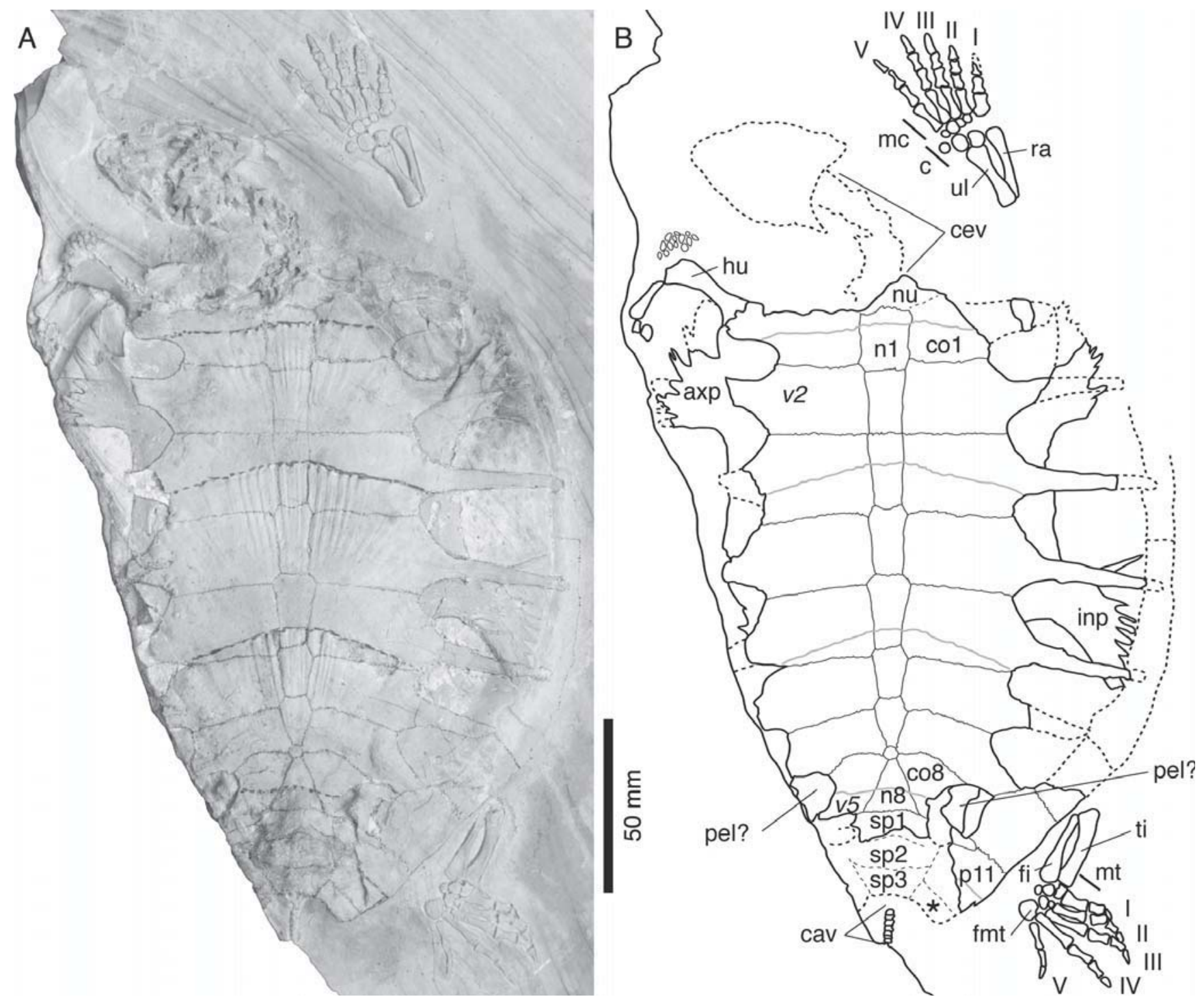

FIGURE 4. BSPG 1960 VIII 43, Eurysternum wagleri, Late Jurassic of Denkendorf/Zandt, Germany. A, photograph of specimen; B, interpretative line drawing. Abbreviations: I-V, digits I through V; axp, axillary process; c, carpals; cav, caudal vertebrae; cev, cervical vertebrae; co, costal; fi, fibula; fmt, fifth metatarsal; hu, humerus; inp, inguinal process; mc, metacarpals; mt, metatarsals; n, neural; nu, nuchal; p, peripheral; pel, pelvis; ra, radius; sp, suprapygal; ti, tibia; ul, ulna; v, vertebral scale; *, supernumerary bone. 


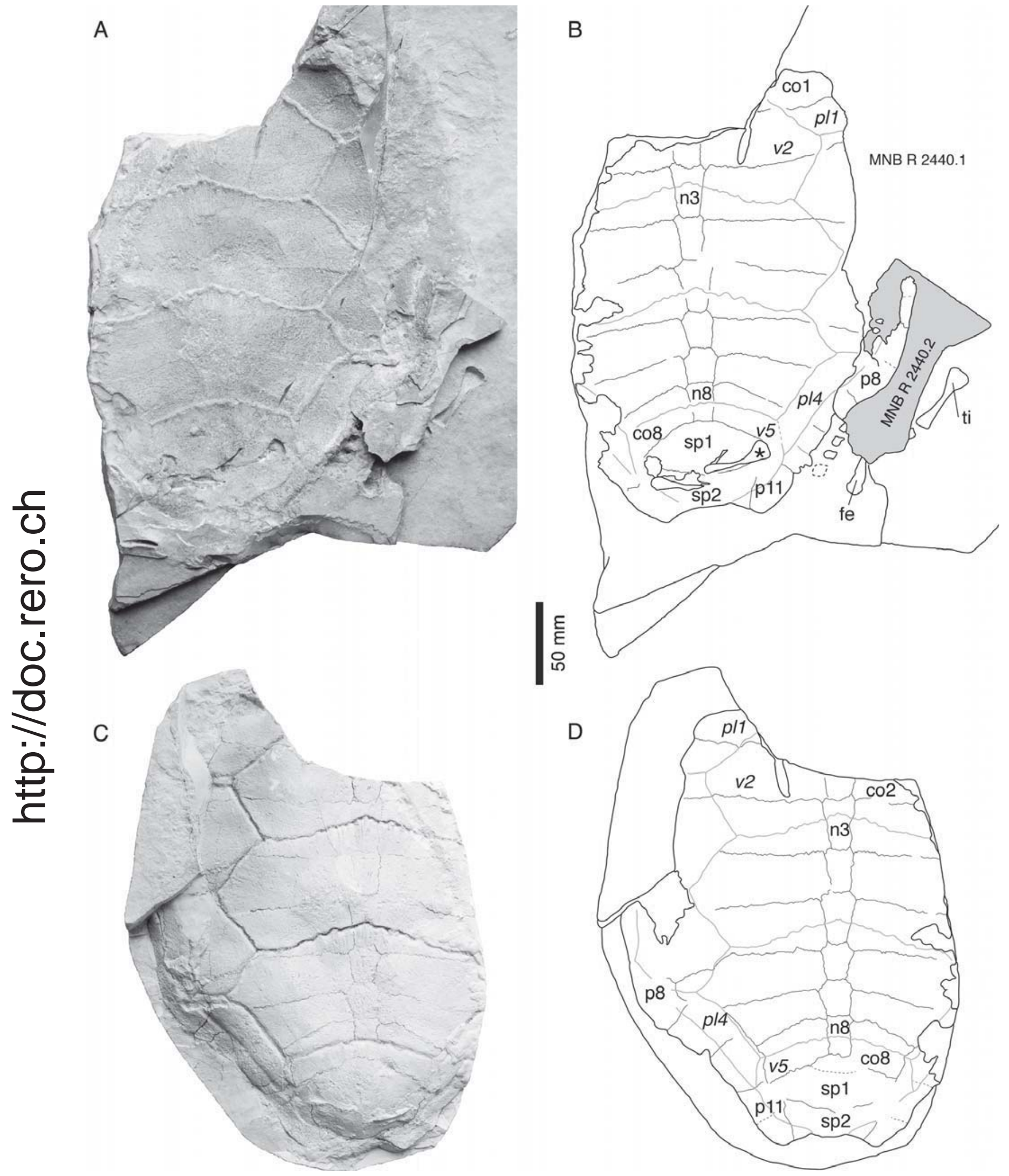

FIGURE 5. MNB R 2440 (lectotype of Acichelys redenbacheri), Eurysternum wagleri, Late Jurassic of Solnhofen, Germany. A, photograph of specimens MNB R 2440.1 and MNB R 2440.2; B, interpretative line drawing of specimens shown in A; C, photograph of the plaster counter mold, MNB R 2440.3; D, interpretative drawing of the plaster counter mold, MNB R 2440.3. Abbreviations: co, costal; fe, femur; n, neural; p, peripheral; pl, pleural scale; $\mathbf{s p}$, suprapygal; ti, tibia; $\mathbf{v}$, vertebral scale; *, dissolution mark. 


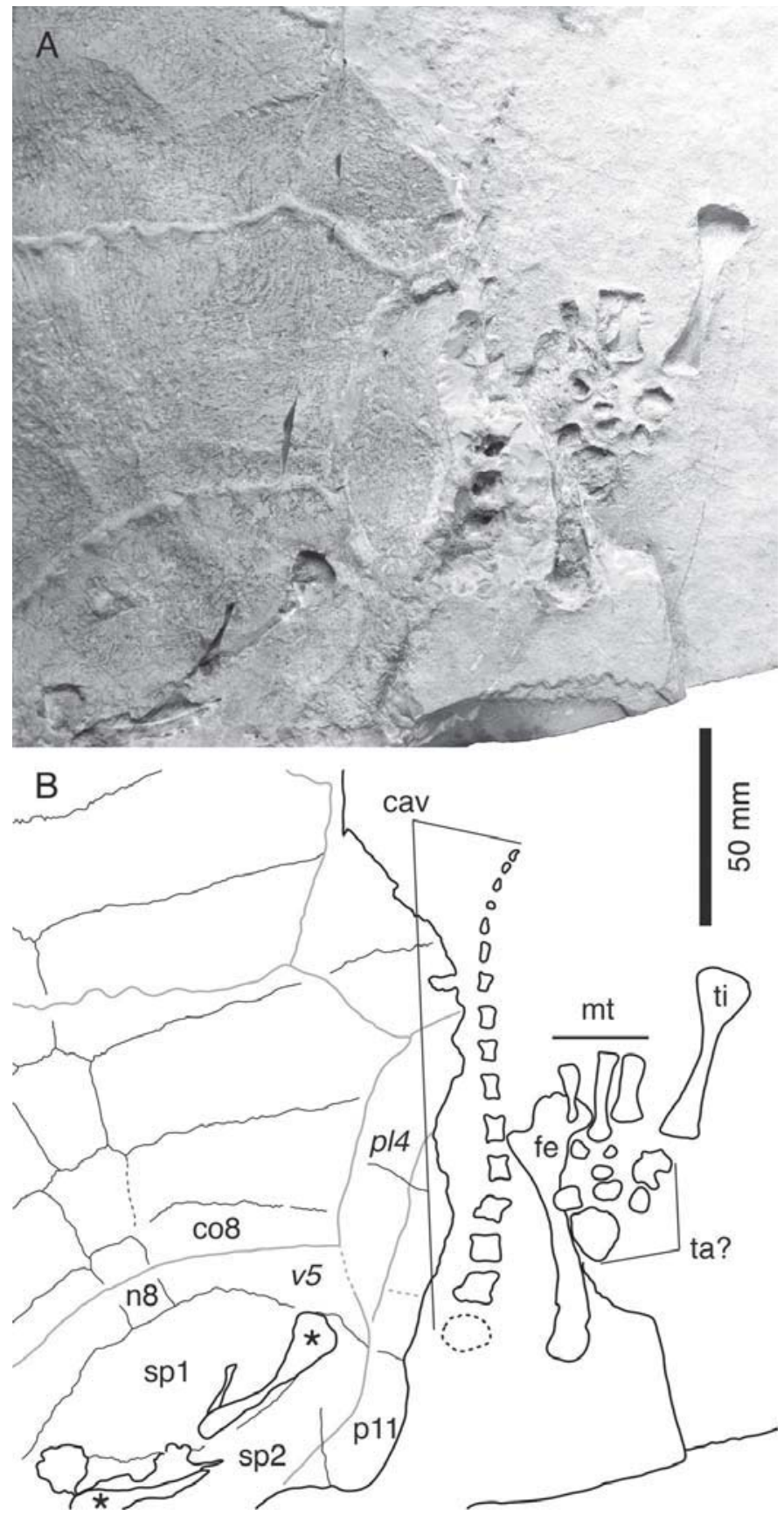

FIGURE 6. MNB R 2440 (lectotype of Acichelys redenbacheri), Eurysternum wagleri, Late Jurassic of Solnhofen, Germany. A, detailed photograph of MNB R 2440.1 with fragment MNB R 2440.2 removed; B, interpretative line drawing. Abbreviations: cav, caudal vertabrae; co, costal; fe, femur; mt, metatarsals; n, neural; p, peripheral; pl, pleural scale; sp, suprapygal; ta, tarsals; ti, tibia; v, vertebral scale; *, dissolution mark.

Liaochelys jiangchangensis (Zhou, 2010). There are 11 peripherals, of which peripherals 9-11 are enlarged. Peripherals 11 form the lateral aspects of the pygal notch on both sides.

As mentioned above, there are three cervical scales, including a very wide median one. The vertebral scales are also very wide. Because of the presence of carapacial fontanelles, the lateral margins of the vertebral scales and the pleural scales themselves are not visible. There is a well-defined radiating pattern on vertebrals $2-4$. Vertebral 5 forms the anteromedial border of the pygal notch, hence contributing to the posterior carapacial margin. The number of marginals is unclear, but 12 pairs appear to be present as in most turtles.

Unfortunately, little can be seen of the plastron, but some aspects are apparent through the costoperipheral fontanelles. The connection between the carapace and plastron was not ossified. Axillary and inguinal processes are characterized by relatively gracile, peg-like projections, compared with those observed in Solnhofia parsonsi (see Joyce, 2000). The axillary process projects far anteriorly and reaches the level of the second peripheral, but it is unclear if the second peripheral possesses a facet for its articulation. Loose connections appear to have furthermore been present with peripherals 3-5. The inguinal process is mainly associated with peripherals 7 and 8 . The posteriormost peg-like projection articulates with a facet in the central portion of peripheral 8. Large, elongated, and oval bridge fontanelles are apparent on both sides.

Little can be said of the appendicular skeleton. The metatarsals and phalanges of the right pes are preserved in articulation. The phalangeal count is 2-3-3-3-3 (the fifth metatarsal is missing), which is a common formula in turtles.

\section{DESCRIPTION OF BSPG 1960 VIII 43}

BSPG 1960 VIII 43 is a yet undescribed specimen from Denkendorf/Zandt, Germany, the same locality as BSPG AS I 921. This is a less complete specimen of comparable size (carapace length $=177 \mathrm{~mm}$ ) that nevertheless provides very interesting indications concerning intraspecific variation in Eurysternum wagleri (Fig. 4). A great part of the left side of the shell was lost due to postdepositional processes. The nuchal and most peripherals are missing, and the skull and cervical vertebrae are poorly preserved. Although they will probably not reveal much, it would be interesting to prepare and study the cranial remains in more details because they are better preserved than those of BSPG AS I 921. The skull is $34.5 \mathrm{~mm}$ in length, which represents about $19.5 \%$ of the carapace length. This corresponds to previous estimates for E. wagleri (Broin, 1994; Joyce, 2000). The appendicular skeleton is represented by the partial left forelimb, the right radius, ulna and manus, and the right hind limb. A short series of six or seven small caudal vertebrae is also present at the level of the pygal notch.

Most of the outline of the carapace is preserved thanks to the impression left by the peripheral series on the surface of the slab. The carapace is pentagonal in outline, with its greatest width at the level of the seventh peripheral. The margin from peripheral 8 to 11 is slightly concave. Many of the bones surrounding the pygal notch are missing, but the limestone slab underneath has kept detailed imprints of their margins. The pygal notch is as deep as in the two previously described specimens, but, unlike BSPG AS I 921, it is flanked by an additional pair of bones of unknown affinities. These may correspond to a twelfth, neomorphic pair of peripherals. Interestingly, this is the exact same morphology as displayed in the illustration of the holotype specimen of E. wagleri (Fig. 1).

The neural series is a little different from that of BSPG AS I 921. Neurals 1-7 match fairly well, except for the posterior part of neural 7, which is greatly reduced in width. Posteriorly to the seventh neural, there is a small rounded bone upon which the sutures of costals 8 converge. Behind this small element, there is an elongate, triangular bone that contacts the first suprapygal posteriorly. By comparison with BSPG AS I 921, we identify this second bone as neural 8 and the small rounded element as a subdivision either of neural 7 or of neural 8 . Such kinds of variations in the neural series regularly occur among other Jurassic turtles (e.g., Rabi et al., 2013). In contrast to BSPG AS I 921 and apparently also to the holotype specimen, there are three suprapygals, 
of which the last two morphologically correspond to the second suprapygal of BSPG AS I 921. The level of ossification of the costal is similar to that of BSPG AS I 921, which is to be expected because the two specimens are approximately of the same size.

Only the intervertebral sulci are visible in the present specimen. The vertebrals are consequently very wide, and there is a well-defined radiating pattern on vertebrals $2-4$. The most lateral parts of the plastron can be seen through the carapacial fontanelles and agree with the morphology seen in BSPG AS I 921. The right manus and pes are entirely preserved. The manual and pedal phalangeal formulae of 2-3-3-3-3 are symplesiomorphic for all crown turtles (Joyce, 2007).

\section{DESCRIPTION OF MNB R 2440, LECTOTYPE OF ACICHELYS REDENBACHERI}

MNB R 2440, the newly designated lectotype of Acichelys redenbacheri (see Discussion) now referred to Eurysternum wagleri, consists of the partial imprint of the external surface of a carapace (Fig. 5A, B). Meyer (1860:pl. XXI, fig. 5) figured this specimen and also illustrated what appears to be the counter slab (Meyer, 1860:pl. XXI, fig. 4), but this material is currently unaccounted for, unless this is actually the plaster counter mold (MNB R 2440.3; Fig. 5C, D) stored alongside the specimen in Berlin. MNB R 2440 is formed of two parts: the main slab (MNB $R$ 2440.1) and a smaller fragment that is approximately $10 \mathrm{~cm}$ long (MNB R 2440.2). This fragment can by lifted in order to reveal further postcranial material (caudal vertebrae and limb bones; see below) associated with the carapacial imprint (Fig. 5A, B).

The morphology of the carapace can be observed directly from the imprint itself, but the plaster counter mold (MNB R 2440.3; Fig. 5C, D) also provides valuable information. Most of the carapacial rim and the anterior part of the carapace are missing, so it is impossible to establish the number of bony plates and scales without doubt. However, for simplicity and owing to the absence of contradictory evidence, the following description assumes a number of eight neurals, eight costals, and 11 peripherals. The carapace length is estimated by comparison with other specimens of E. wagleri to have been slightly more than $300 \mathrm{~mm}$. The carapace width is more difficult to appreciate because the specimen may have been flattened during fossilization. The posterior outline of the carapace recalls that of the holotype of E. wagleri in being teardrop-shaped, with the maximum carapace width at the level of the seventh peripheral. The concavity of the carapacial rim along peripherals $8-11$ appears to be more pronounced in this specimen, but this might be a preservational bias. A similar morphology is apparent from two of the lost specimens illustrated in Meyer (1860:pl. XIX, fig. 2; pl. XXI, fig. 3; see Discussion).

Neurals 3-8 are hexagonal and elongate. Anteriorly, only the posterior half of neural 2 is visible. Costals $1-8$ can be seen on the right side of the imprint, which corresponds to the left side of the animal. Costals 1 and 2 are slightly concave anteriorly, as it is the case in many turtles. Meyer $(1854,1860)$ noted that the costals alternately widen and narrow distally and used this purported characteristic as a central diagnostic trait of this taxon, but we cannot confirm this morphology. The contact between costals and peripherals is only preserved posteriorly for costals 6-8. At least in that area, there are no carapacial fontanelles. Peripherals 6-11 are present on the right side of the imprint, whereas only peripherals 10 and 11 are preserved on the opposite side. There is no median contact between the eleventh peripherals due to the presence of a seemingly shallow but wide pygal notch.
The detailed anatomy of the pygal region is uncertain. Posterior to neural 8 , there appear to be two large suprapygals. The anterior one is triangular in shape. The posterior one, only slightly smaller, is semilunate and forms the median part of the pygal notch border. The counter plaster mold suggests that there may have been a third, smaller suprapygal element just behind neural 8 , although this cannot be confirmed by the direct observation of the imprint.

The contact between the first and second suprapygals is only partly preserved on the imprint and appears to be concave anteriorly. This contact is partly masked by cavities left after the dissolution of two bones of uncertain affinity. In addition to these dissolution marks, the surface of the imprint is damaged leaving cavities with irregular outlines (Fig. 6). Two of these cavities are confluent with the dissolution marks and are apparently not part of the original morphology of the carapace. Meyer's (1860:pl. XXI, figs. 4, 5) illustration suggests that a third, rounded cavity on the left side of the imprint is natural. Such morphology would recall the small pygal fontanelles found in the holotype of Eurysternum wagleri and BSPG AS I 921. A detailed study of this rounded cavity in MNB R 2440 shows that its outline is irregular and that this structure does not appear to be paired (Fig. 6). This cavity is therefore interpreted as being unnatural. Two of the lost specimens illustrated in Meyer (1860) show some variation in the pygal region. One of these (Meyer, 1860:pl. XIX, fig. 2) lacks pygal fontanelles, but has three suprapygals like BSPG 1960 VIII 63 and an additional more rounded element behind neural 8 . The other, by contrast, has only two suprapygals and shows a minor pygal fontanelle between the eighth costal, the first suprapygal and the two last peripherals (Meyer, 1860:pl. XXI, fig. 3).

Scale sulci are clearly apparent on the imprint as pronounced ridges. Vertebral 1, most of the pleurals, and the marginals are not preserved. Vertebrals 2-4 are wide scales that broadly cover the costal bones. A radiating pattern is present on vertebrals 3 and 4 (probably also in vertebral 2, but the anterior part of this scale is missing). Vertebral 5 is smaller and contributes to the median part of the pygal notch. Intervertebral sulci are sinusoidal. Pleural scales are only preserved on the right side of the imprint. Of pleurals $1-3$, only the median half is visible and shows that the contacts with vertebral scales are oblique. Because of the great lateral extension of the fourth vertebral scale, pleural 4 is elongate, very narrow, and almost exclusively located on peripherals. Some intermarginal sulci are visible (e.g., on peripherals 6 and 10), but nothing concrete can be said about marginals.

Associated with the carapacial imprint are some postcranial elements preserved as dissolution cavities (Fig. 6). A series of 15-16 caudal vertebrae that correspond to a moderately long and relatively thin tail are preserved lying parallel to the posterior border of the carapace. The vertebrae are preserved as quadrangular cavities that provide no information regarding their original morphology. A series of long bones and smaller elements that correspond to the left hind limb of the animal are preserved next to the tail. The element on the left, closer to the caudal vertebrae, can be confidently identified as the femur (in lateral view). Some trabecular bone is preserved in the distal head. The femur is elongate and presents a moderate curvature. This is comparable to the morphology found in extant freshwater turtles. The element on the right is the tibia (probably in frontal view), with a triangular, well-developed proximal head. Between the distal end of the tibia and the proximal head of the femur are smaller, elongate elements that are probably metatarsals. Along the femur, a series of even smaller indeterminable dissolution cavities may correspond to tarsal elements. 


\section{DISCUSSION}

\section{Characteristics of Eurysternum wagleri}

The purpose of the present paper is to highlight the fact that all Late Jurassic turtles from southern Germany characterized by the presence of a deep pygal notch are actually also united by a set of other characters allowing a recharacterization of the species Eurysternum wagleri. These characteristics are summarized below.

Because so many specimens have been referred to and species synonymized with $E$. wagleri over the years, the size range of this species has remained somewhat unclear. Based on the present reassessment, it appears that $E$. wagleri is a turtle of moderate size, with larger individuals reaching about $350-400 \mathrm{~mm}$ in carapace length. The costoperipheral fontanelles are closed when specimens reach this size (see specimens previously identified as Acichelys redenbacheri), and such specimens can therefore be presumed to be skeletally mature. As exemplified by BSPG AS I 921 and BSPG 1960 VIII 43, there are also many fossils of medium-sized individuals (150-200 mm) with extensive carapacial fontanelles. The skull represents about $20 \%$ of the carapace length.

The carapace is longer than wide and pentagonal in outline, with its greatest width at the level of peripherals 7-8. There is a broad nuchal notch formed exclusively by the nuchal. The posterior carapace margin is somewhat pinched, which means that there is a sudden reduction in width from peripheral 8-11. There, the margin is slightly concave. Posteriorly, there is a deep pygal notch that appears to result from the complete loss of the pygal bone (see discussion below).

The nuchal is trapezoidal and very wide. There are generally two suprapygals, but some individuals have three. An additional pair of bones sometimes forms the lateral margins of the pygal notch. These bones have the anatomical position of neomorphic, twelfth peripherals, but their exact identity remains unclear (see discussion below). As discussed above, we interpret the occurrence of this additional pair of bones as an individual variation.

There are three cervical scales, with the median one being significantly wider than the others. The vertebral scales are also very wide. In medium-sized specimens, the lateral margins of the vertebrals and the pleural scales are located above the costoperipheral fontanelles. There is a well-developed radiating pattern on vertebrals $2-4$. This radiating pattern is also retained in the largest individuals. Because of the presence of the deep pygal notch, the fifth vertebral scale enters the posterior carapace margin and marginals 12 therefore lack a median contact on the dorsal surface of the shell.

Based exclusively on the specimens described herein, little is known of the plastron of $E$. wagleri. The connection between the carapace and the plastron is ligamentous. The axillary and inguinal processes form rather gracile, peg-like bony projections. These are respectively located mainly at the level of peripherals 3-4 and peripherals 7-8. The axillary process extends far anteriorly and reaches the level of the second peripheral, but apparently has no contact with the costals. There is a large, quadrangular to oval lateral plastral fontanelle on each side.

The lithographic limestone quarries of southern Germany have produced several undescribed specimens referable to Eurysternum wagleri that are preserved on their back and show the plastron. This is notably the case in SMF R 4181 from Solnhofen (figured in Frickhinger, 1994:fig. 508), CM 3409 (unknown locality), and at least two uncataloged specimens from Painten exhibited at BMM. In these specimens, there is a large central plastral fontanelle. Interestingly, the central plastral fontanelle is wider than long, which is rather unusual. The epiplastra and the entoplastron were connected to hyoplastra by connective tissue and are lost in most specimens. Indeed, it is unclear if these bones were ossified at all, as in other eurysternids (Joyce, 2000).
Hyoplastra, hypoplastra, and xiphiplastra are not sutured on the midline, even in larger individuals (SMF R 4181 would have had a carapace length of about $310 \mathrm{~mm}$ ). There are medial, peg-like projections on the hyoplastra and hypoplastra. Similar projections are also present on the posterior part of the xiphiplastra, likely framing a xiphiplastral fontanelle. This plastral morphology is clearly different from that of other known eurysternids, such as Solnhofia parsonsi (Joyce, 2000) or Idiochelys fitzingeri (Meyer, 1839a, 1840).

\section{Remarks on Acichelys redenbacheri}

Several problems are associated with the taxon Acichelys redenbacheri. First, unlike all other taxa from the Late Jurassic of Germany, A. redenbacheri was typified based on a series of unrelated specimens from different quarries and strata, which are predominantly united by their large size relative to other named taxa and by the presence of a deep pygal notch. Second, because Meyer $(1843,1854)$ did not explicitly list specimens in the type description, it is unclear which specimens are parts of the type series, with the exception of the Redenbacher specimen. Third, and again with the exception of the Redenbacher specimen, all syntype material is lost. As a solution to the problems associated with the unclear identity of Acichelys redenbacheri and the loss of most syntypes, the Redenbacher specimen (MNB $\mathrm{R} 2440$ ) is herein designated as the lectotype, rendering it the unique bearer of the name and the standard for its application. A review of the Redenbacher specimen reveals considerable differences compared with the morphologies illustrated and described by Meyer (1860). The illustration of the still available slab (Meyer, 1860:pl. XXI, fig. 5) lacks considerable amounts of clearly observable traits of the sulci, whereas the pygal region exhibits details that cannot be seen in the specimen. Furthermore, the depicted bony sutures do not fully correspond with those observable in the specimen, and the outline of the specimen (a diagnostic character used by Meyer) appears to be a preservational artifact, because most of the posterior region of the specimen has not been prepared and is still covered by sediments. The lectotype, however, clearly show the presence of a deep pygal notch and a contribution of vertebral 5 to the posterior carapacial margin, two rare characters only found in Eurysternum wagleri. We therefore herein interpret Acichelys redenbacheri Meyer, 1854, as a junior subjective synonym of Eurysternum wagleri Meyer, $1839 \mathrm{~b}$.

\section{Variation in the Pygal Region of Eurysternum wagleri}

The configuration of the pygal region of Eurysternum wagleri is unique among turtles, even if some resemblances are apparent with the shell of various other, unrelated taxa. Homology of the various elements is particularly difficult to understand in this region. Instead of being formed by a simple emargination of the pygal, the deep pygal notch of E. wagleri appears to be the result of the complete loss of this bone, although it is similarly possible that the pygal moved anteriorly between the peripherals and that a suprapygal was lost instead. For simplicity, the two or three elements posterior to the eighth neural are herein referred to as suprapygals. In derived baenids and in Sinemys spp., the fifth vertebral also contributes to the posterior margin of the shell, but the pygal notch is only shallow and a well-developed bone typically interpreted as the pygal is retained (Gaffney, 1972; Brinkman and Peng, 1993; Lyson and Joyce, 2010; Tong and Brinkman, 2013).

As apparent from the above descriptions, the configuration of the pygal region is subject to a certain degree of individual variation. There is variability in the number of suprapygals. For instance, BSPG 1960 VIII 43, one of the lost specimens illustrated by Meyer (1860:pl. XIX, fig. 2), and possibly also MNB R 2440 have three suprapygals, instead of two. However, such 
variability is rather common among turtles and is considered to be of poor systematic value. Zangerl (1969) noted that the mosaic of bones in the pygal region was more variable than the rest of the shell, perhaps because these bony plates are not intimately connected to the axial skeleton.

A more striking variability observed in E. wagleri is the sporadic presence of an additional pair of elements behind the eleventh peripherals. These additional elements are known from the holotype specimen (as far as the original illustration can be trusted) and from BSPG 1960 VIII 43. They form the lateral margins of the pygal notch. They are significantly shorter than preceding peripherals, representing about one-quarter of the length of the eleventh peripheral. The identity of these elements remains conjectural. A twelfth pair of peripherals occurs as an irregular variation in some turtles (Zangerl, 1969). Joyce (2003) suggested that if the presence of this additional pair of bones in the holotype was to be confirmed, then a specific distinction between the holotype and Zittel's specimen BSPG AS I 921 may be warranted. However, a wider review now reveals that Late Jurassic turtles with a deep pygal notch are united by a combination of characters that unambiguously separates them from other European forms and strongly suggests that they are conspecific. We therefore interpret the presence of an additional pair of elements behind the eleventh peripherals as intraspecific variation.

\section{Presence of Three Cervical Scales}

The presence of three cervical scales in Eurysternum wagleri is not new per se, as Bräm (1965) already mentioned this characteristic for the Zittel's specimen BSPG AS I 921. However, this piece of information was overlooked by all following authors (e.g., Lapparent de Broin et al., 1996; Joyce, 2000, 2003; Lapparent de Broin, 2001). Indeed, many studies emphasized the presence of three cervical scales as a key character for the diagnosis of Plesiochelyidae (Bräm, 1965; Lapparent de Broin et al., 1996; Slater et al., 2011; Püntener et al., 2014; Pérez-García, in press). However, as pointed out by Joyce (2003), it has long been known that Palaeomedusa testa also has three cervicals. Neither P. testa nor $E$. wagleri is typically considered to be a plesiochelyid, indicating that this character is more widespread than previously thought. The distribution of this character among Late Jurassic turtles should ultimately be tested in a phylogenetic context, but it should also be kept in mind that cervical scale sulci are not always readily observable in fossil specimens, including many Plesiochelys shells (pers. observ.). Because three cervicals are present in Eurysternum wagleri and Palaeomedusa testa, we predict that they may eventually be found in other eurysternids as well, such as Solnhofia parsonsi.

\section{Specimens and Taxa Similar to Eurysternum wagleri}

Eurysternum wagleri is the type species of the genus Eurysternum. Over the years, several taxa have been proposed to be close relative of this species. These notably include specimens from the Kimmeridgian of Cerin, France, referred to Eurysternum crassipes by Lortet (1892), the taxon Eurysternum ignoratum from the Kimmeridgian of Solothurn, Switzerland (Bräm, 1965), and material identified as Eurysternum sp. from the Tithonian of Canjuers, France (Broin, 1994).

The specimens from Cerin referred by Lortet (1892) to Eurysternum crassipes Wagner, 1861 (a junior objective synonym of Palaeomedusa testa Meyer, 1860; see Joyce, 2003), are in need of revision. This material is housed in Lyon, France, and includes several limbs, but also partial shell and cranial remains (Lortet, 1892; Lapparent de Broin, 2001).

Eurysternum ignoratum Bräm, 1965, was erected based on material from Solothurn, Switzerland. Bräm (1965) conceptualized the distinction between Eurysternidae, Thalassemydidae, and Plesiochelyidae based mainly on the morphology of the plastron. In particular, eurysternids were diagnosed by the presence of lateral and central fontanelles, thalassemydids by the presence of a large central fontanelle, and plesiochelyids by the presence of a small central fontanelle at most. NMS 5, the holotype of E. ignoratum, is clearly distinguished by the presence of lateral and central fontanelles and by the retention of generously developed carapacial fontanelles between costals and peripherals. These characteristics are also found in E. wagleri. However, Bräm (1965) correctly noted that the width of the vertebral scales of NMS 5 was greatly reduced compared with E. wagleri, warranting a specific distinction. Based on the above updated description, it is undeniable that E. wagleri and E. ignoratum are at least separate species.

Broin (1994) provided a preliminary description of the fossil turtles from the Tithonian of Canjuers, France, and identified one specimen (MNHN CNJ 77; Broin, 1994:pl. 1, fig. 7) as Eurysternum sp. As in E. wagleri, the carapace is pentagonal in outline, with its greatest width around peripheral 7 , vertebral scales are very wide, there is a pronounced radiating pattern on vertebrals $2-4$, and the skull represents about $20 \%$ of the carapace length. However, the specimen lacks a pygal notch, the posterolateral rim of the carapace is not slightly concave, and peripherals 7-11 are very wide, characters that are otherwise present in Solnhofia parsonsi (Joyce, 2000). A detailed description of this specimen will be published elsewhere, but our preliminary observations agree with Broin (1994) that this specimen is different from $E$. wagleri.

A series of taxa from the Late Jurassic of Europe (mostly from Solnhofen, Germany) were synonymized with E. wagleri over the course of the last 100 years, including Aplax oberndorferi (as first proposed by Zittel, 1877), Achelonia formosa, Euryaspis radians, Palaeomedusa testa (as first proposed by Rütimeyer, 1873), Hydropelta meyeri, Parachelys eichstaettensis (as first proposed by Oertel, 1915), and Thalassemys marina (as first proposed by Bräm, 1965). Aplax oberndorferi is based on a complete, juvenile specimen (Meyer, 1843), but it lacks all diagnostic characters of $E$. wagleri. Indeed, the specimen is so small and poorly ossified that it should be considered an indeterminate turtle. The same arguments can be made for Achelonia formosa from Cerin, France, which is also based on a poorly ossified, juvenile specimen (Meyer, 1860). Euryaspis radians is based on the central portion of a carapace and only displays the presence of wide vertebral scales, a character that is widely distributed among Jurassic turtles and generally thought to be a symplesiomorphy (e.g., Joyce, 2007). Hydropelta meyeri is based on a fragmentary fossil from Cerin, France (Thiollière, 1850). This specimen is notable for having anterior plastral buttresses that resemble those of E. wagleri, but we are uncertain about the distribution of this character and suspect that it is diagnostic for several eurysternid taxa. The specimen otherwise lacks characters of diagnostic value. Similarly, Parachelys eichstaettensis is based on yet another partial specimen (Meyer, 1864), and it is therefore again not possible to find any diagnostic characters in the shell that might unite it with E. wagleri. However, the unusual manual phalangeal formula of Parachelys eichstaettensis (2-2-3-3-3) differs from that of E. wagleri (see above), which allows us to reject a synonymy. We finally also reject the synonymy with Palaeomedusa testa because the cervical region of the holotype of this taxon is significantly narrower than that of E. wagleri.

\section{CONCLUSIONS}

One of the first named fossil turtles from the Late Jurassic of Europe, Eurysternum wagleri is also one of the most distinctive. Up until now, however, its proper identification was hindered by the need for a long overdue taxonomic reassessment. Based on a revision of characteristic specimens, we reject all previously 
proposed synonymies except for the one with Acichelys redenbacheri.

The holotype of Eurysternum wagleri is lost, but the original illustration provides enough information to allow an unambiguous recognition of the species. The shape of the carapace and the configuration of its posterior part are particularly characteristic. All specimens exhibiting a deep pygal notch similar to that of the aforementioned holotype also share a number of other characters that clearly differentiate them from other Late Jurassic European forms, warranting the validity of the species.

The Late Jurassic turtle fauna from Europe is incredibly rich and diverse, but it is also sparsely studied. A detailed taxonomic reevaluation of the historical material must be engaged. There is also a significant amount of undescribed material in museum collections throughout Europe.

\section{ACKNOWLEDGMENTS}

We thank the following people for providing access to specimens in their care: O. Rauhut and A. López-Arbarello (BSPG), J. Müller (MNB), S. Thüring (NMS), R. Allain (MNHN), M. Röper (BMM), and M. Lamanna (CM). The high-resolution photograph of the illustration of the holotype of Eurysternum wagleri in Figure 1 was produced by the Photo Unit of the Natural History Museum, London. I. Danilov, M. de la Fuente, M. Rabi, and J. Sterli are thanked for thoughtful comments and/or discussion that helped improve the quality of the manuscript. J. A. was funded by a postdoctoral grant from the Simone and Cino del Duca Foundation (2008 Foundation Prize awarded to P. Janvier, MNHN).

\section{LITERATURE CITED}

Batsch, A. J. G. C. 1788. Versuch einer Anleitung, zur Kenntniß und Geschichte der Thiere und Mineralien. Akademische Buchhandlung, Jena, 528 pp.

Baur, G. 1888. Osteologische Notizen über Reptilien (Fortsetzung III). Zoologischer Anzeiger 11:417-424.

Bräm, H. 1965. Die Schildkröten aus dem oberen Jura (Malm) der Gegend von Solothurn. Schweizerische Paläontologische Abhandlungen 83:1-190.

Brinkman, D. B., and J.-H. Peng. 1993. New material of Sinemys (Testudines, Sinemydidae) from the Early Cretaceous of China. Canadian Journal of Earth Sciences 30:2139-2152.

Broin, F. de. 1994. Données préliminaires sur les chéloniens du Tithonien inférieur des calcaires lithographiques de Canjuers (Var, France). Geobios 16:167-175.

Danilov, I. G. 2005. Die fossilen Schildkröten Europas; pp. 329-441 in U. Fritz (ed.), Handbuch der Reptilien und Amphibien Europas. Band 3/IIIB: Schildkröten (Testudines) II. Aula-Verlag, Wiebelsheim, Gemany.

Dollo, L. 1886. Première note sur les chéloniens du Bruxellien (Éocène moyen) de la Belgique. Bulletin Du Musée Royal d'Histoire Naturelle de Belgique 4:75-100.

Fraas, E. 1903. Thalassemys marina E. Fraas aus dem oberen weissen Jura von Schnaitheim nebst Bemerkungen über die Stammesgeschichte der Schildkröten. Jahreshefte Des Vereins Für Vaterländische Naturkunde in Württemberg 59:72-104.

Frickhinger, K. A. 1994. Die Fossilien von Solnhofen. Golschneck-Verlag, Korb, Germany, 336 pp.

Gaffney, E. S. 1972. The systematics of the North American family Baenidae (Reptilia, Cryptodira). Bulletin of the American Museum of Natural History 147:241-320

Gaffney, E. S. 1975a. A phylogeny and classification of the higher categories of turtles. Bulletin of the American Museum of Natural History 155:387-436.

Gaffney, E. S. 1975b. Solnhofia parsonsi, a new cryptodiran turtle from the Late Jurassic of Europe. American Museum Novitates 2576:1-25.

Joyce, W. G. 2000. The first complete skeleton of Solnhofia parsonsi (Cryptodira, Eurysternidae) from the Upper Jurassic of
Germany and its taxonomic implications. Journal of Paleontology 74:684-700.

Joyce, W. G. 2003. A new Late Jurassic turtle specimen and the taxonomy of Palaeomedusa testa and Eurysternum wagleri. PaleoBios 23:1-8.

Joyce, W. G. 2007. Phylogenetic relationships of Mesozoic turtles. Bulletin of the Peabody Museum of Natural History 48:3-102.

Lapparent de Broin, F. de. 2001. The European turtle fauna from the Triassic to the Present. Dumerilia 4:155-217.

Lapparent de Broin, F. de, B. Lange-Badré, and M. Dutrieux. 1996. Nouvelles découvertes de tortues dans le Jurassique supérieur du Lot (France) et examen du taxon Plesiochelyidae. Revue de Paléobiologie 15:533-570.

Lortet, L. 1892. Les reptiles fossiles du bassin du Rhône. Archives du Muséum d'Histoire Naturelle de Lyon 5:1-139.

Lyson, T. R., and W. G. Joyce. 2010. A new baenid turtle from the Late Cretaceous (Maastrichtian) Hell Creek Formation of North Dakota and a preliminary taxonomic revision of Cretaceous Baenidae. Journal of Vertebrate Paleontology 30:394-402.

Maack, G. A. 1869. Die bis jetzt bekannten fossilen Schildkröten und die im oberen Jura bei Kelheim (Bayern) und Hannover neu aufgefundenen ältesten Arten derselben. Palaeontographica 18:193-338.

Meyer, H. von. 1839a. Idiochelys fitzingeri, eine Schildkröte aus dem Kalkschiefer von Kelheim. Beiträge zur Petrefacten-Kunde 1:59-74.

Meyer, H. von. 1839b. Eurysternum wagleri, Münster. Eine Schildkröte aus dem Kalkschiefer von Solnhofen. Beiträge zur PetrefactenKunde 1:75-82.

Meyer, H. von. 1839c. Mittheilungen an Professor Bronn gerichtet. Neues Jahrbuch für Mineralogie, Geognosie, Geologie und Petrefaktenkunde 1839:76-79.

Meyer, H. von. 1840. Idiochelys wagneri. H. v. Meyer. Aus dem Kalkschiefer von Kelheim. Beiträge zur Petrefacten-Kunde 3:11-18.

Meyer, H. von. 1843. Mittheilungen an Professor Bronn gerichtet. Neues Jahrbuch für Mineralogie, Geognosie, Geologie und Petrefaktenkunde 1843:579-590.

Meyer, H. von. 1854. Mittheilungen an Professor Bronn gerichtet. Neues Jahrbuch für Mineralogie, Geognosie, Geologie und Petrefaktenkunde 1854:575-581.

Meyer, H. von. 1860. Zur Fauna der Vorwelt. Reptilien aus dem lithographischen Schiefer des Jura in Deutschland und Frankreich. Heinrich Keller, Frankfurt am Main, 142 pp.

Meyer, H. von. 1864. Parachelys eichstättensis aus dem lithographischen Schiefer von Eichstätt. Palaeontographica 11:289-295.

Oertel, W. 1915. Beiträge zur Kenntnis der oberjurassischen Schildkrötengattung Hydropelta. Centralblatt für Mineralogie, Geologie und Paläontologie 1915:336-348.

Pérez-García, A. In press. Reinterpretation of the Spanish Late Jurassic "Hispaniachelys prebetica" as an indeterminate plesiochelyid turtle (Testudines, Pancryptodira). Acta Palaeontologica Polonica.

Püntener, C., J. -P. Billon-Bruyat, L. Bocat, J. -P. Berger, and W. G. Joyce. 2014. Taxonomy and phylogeny of the turtle Tropidemys langii Rütimeyer, 1873, based on new specimens from the Kimmeridgian of the Swiss Jura Mountains. Journal of Vertebrate Paleontology 34:353-374.

Rabi, M., C.-F. Zhou, O. Wings, S. Ge, and W. G. Joyce. 2013. A new xinjiangchelyid turtle from the Middle Jurassic of Xinjiang, China and the evolution of the basipterygoid process in Mesozoic turtles. BMC Evolutionary Biology 13:203 < doi:10.1186/1471-2148-13-203>

Rütimeyer, L. 1873. Die fossilen Schildkröten von Solothurn und der übrigen Juraformation. Neues Denkschrift der Allgemeinen Schweizerischen Gesellschaft für die Gesammten Naturwissenschaften 25:1-185.

Slater, B. J., M. Reolid, R. Schouten, and M. J. Benton. 2011. A new Late Jurassic turtle from Spain: phylogenetic implications, taphonomy and palaeoecology. Palaeontology 54:1393-1414.

Thiollière, V. 1850. Continuation des indications sommaires sur les espèces fossiles d'animaux et végétaux recueillies dans le gisement de Cirin. Annales des Sciences Physiques et Naturelles d'Agriculture et d'Industrie de Lyon 32:128-129.

Tong, H., and D. B. Brinkman. 2013. A new species of Sinemys (Testudines: Cryptodira: Sinemydidae) from the Early Cretaceous of Inner Mongolia, China. Palaeobiodiversity and Palaeoenvironments 93:355-366.

Wagner, A. 1853. Beschreibung einer fossilen Schildkröte und etlicher anderer Reptilien-Ueberreste aus den lithographischen Schiefern 
und dem Grünsandsteine von Kelheim. Abhandlungen der Königlish Bayerischen Akademie der Wissenschaften, Zweite Classe 7:241-264.

Wagner, A. 1861. Schildkröten und Saurier aus dem lithographischen Schiefer. Abhandlungen der Königlich Bayerischen Akademie der Wissenschaften, Mathemat.-Physikalischen Classe 9:67-124.

Wellnhofer, P. 1967. Ein Schildkrötenrest (Thalassemydidae) aus den Solnhofener Plattenkalken. Mitteilungen der Bayerischen Staatssammlung für Paläontologie und Historische Geologie 7:181-192.

Zangerl, R. 1969. The turtle shell; pp. 311-339 in C. Gans, A. A. Bellairs, and T. S. Parsons (eds.), Biology of the Reptilia. Volume 1, Morphology A. Academic Press, London.
Zhou, C.-F. 2010. A new eucryptodiran turtle from the Early Cretaceous Jiufotang Formation of western Liaoning, China. Zootaxa 2676:45-56.

Zittel, K. A. 1877. Bemerkungen über die Schildkröten des lithographischen Schiefers in Bayern. Palaeontographica 24:175-184.

Zittel, K. A. 1889. Handbuch der Palæontologie, Abtheilung 1: Palaeozoologie, Band 3, Vertebrata, Lieferung 3: Reptilia. R. Oldenbourg, Munich, $900 \mathrm{pp}$ 